\title{
Discussion: Traffic generated by office and retail developments in Singapore
}

Y. W. Tan and H. S. L. Fan

\section{S. Bowers, Daventry District Council}

In their interesting paper, Y. W. Tan and H. S. L. Fan discuss the outcomes of their work on traffic generated by developments in Singapore; their results are a salutary reminder of the importance of understanding local factors in transport planning.

However, the paper leaves a query. One of the key conclusions was that there is a good correlation between development floor area and traffic generated. However, in section 5.3 they comment that:

'Although highly correlated with traffic generated, the number of parking spaces was considered not suitable as it is derived from floor areas following zoning regulations.'

Given that they also note that people in Singapore do not generally walk far from parking place to final destination (section 3), this raises a question. Were the on-site car parks generally full? If so, this would suggest that the correlation between floor space and traffic generation is actually a result of Singapore's planning regulations, and could therefore change if the regulations were altered.

The authors' reflections on this point would be welcome. (It is acknowledged that the noted effect of proximity of offices to a mass rapid transit (MRT) station slightly complicates the question.)

\section{Authors' reply}

We thank Mr Simon Bowers for his discussion contribution on the influence of planning regulations (and indeed, other traffic management policies) on trip generation.

First, we wish to clarify the point made in our paper in section 5.3 (p. 195) regarding the use of 'number of parking spaces' as an independent variable in the regression equations that were evaluated. From our data, traffic generated by a development was found to be more highly correlated with floor area (gross floor and gross leasable) than with number of parking spaces. We therefore selected floor area as the primary independent variable in the regression equations. To include number of parking spaces and floor area in the same equation would introduce the problem of multi-collinearity, and would result in a less meaningful model.

From our data, the on-site car parks sites were generally not fully utilised. Parking occupancy averaged about 77\% across all office sites. For retail sites, they were generally close to full occupancy during the weekend. As we mentioned in section 3 (p. 191), the parking demand at all sites surveyed was generally satisfied by the on-site car parks provided. We wish to point out that vehicle traffic generated by the site covered not only traffic entering and exiting the car parks, but also vehicles that dropped off or picked up passengers (e.g. taxis), and vehicles that loaded or unloaded goods at the site (e.g. commercial vehicles). Taxis were an important mode to/from certain sites, especially shopping centres, owing to the relatively inexpensive fares in Singapore.

Mr Bowers has raised an important point that trip generation relationships could change when planning regulations change. For instance, when parking supply is rendered more restrictive by limiting the number of spaces per development area or by increasing the parking fee, this could translate to unsatisfied parking demand for some motorists. Depending on the situation, they may decide to park elsewhere, choose a different mode of travel, or choose a different destination. We are in agreement with him on this point, as section 1 (p. 189) of our paper states:

'However, traffic generated by developments can be influenced by various factors, such as differences in levels of vehicle ownership, demand management policies, use of public transport services and the nature of land development.'

(Indeed, these were what motivated us to develop trip generation rates for Singapore conditions.) To this extent, we have been able to identify the effect of proximity to an MRT station on office trip generation during the morning peak hour (equations (3) and (4), p. 196), and the effect of road pricing on retail trip generation during the weekday evening peak hour (equations (7) and (8), p. 197). The trip generation rates and equations determined in the study therefore relate to prevailing conditions during the time of survey. 